\title{
Force-perturbation analysis of Pine Island Glacier, Antarctica, suggests cause for recent acceleration
}

\author{
Robert THOMAS, ${ }^{1,5}$ Eric RIGNOT, ${ }^{2,5}$ Pannirselvam KANAGARATNAM, ${ }^{3}$ \\ William KRABILL, ${ }^{4}$ Gino CASASSA ${ }^{5}$ \\ ${ }^{1}$ EG\&G Services, NASA Wallops Flight Facility, Building N-159, Wallops Island, VA 23337, USA \\ E-mail: thomas@osb.wff.nasa.gov \\ ${ }^{2}$ Jet Propulsion Laboratory, California Institute of Technology, 4800 Oak Grove Drive, Pasadena, CA 91109-8099, USA \\ ${ }^{3}$ Radar Systems and Remote Sensing Laboratory, University of Kansas, 2335 Irving Hill Road, Lawrence, KS 66045-7612, USA \\ ${ }^{4}$ Code 972, NASA Wallops Flight Facility, Building N-159, Wallops Island, VA 23337, USA \\ ${ }^{5}$ Centro de Estudios Cientificos, Av. Arturo Prat 514, Valdivia, Casilla 1469, Chile
}

\begin{abstract}
Pine Island Glacier, flowing into the Amundsen Sea from West Antarctica, thinned substantially during the 1990s, its grounding line receded by several $\mathrm{km}$, and its velocity increased by $>10 \%$ to values approaching $3 \mathrm{~km} \mathrm{a}^{-1}$. Here, we use these observations, together with estimates of ice thickness and surface strain rates, to estimate the perturbation in forces resisting ice flow compatible with the observations. The analysis assumes that such perturbations are transmitted far upstream from where they originate, and that creep response to the perturbations can be described by equations similar to those that govern ice-shelf creep. It indicates that observed acceleration between 1996 and 2000 could have been caused by progressive ungrounding within the most seaward $25 \mathrm{~km}$ 'ice plain' of the grounded glacier. Earlier retreat and thinning of the glacier's floating ice shelf may have provided the conditions that initiated ungrounding of the ice plain. Our analysis indicates that continued ice-plain thinning at the current rate of about $2 \mathrm{~m} \mathrm{a}^{-1}$ will result in a velocity increase by $1 \mathrm{~km} \mathrm{a}^{-1}$ within the next 11 years as the ice plain becomes totally ungrounded.
\end{abstract}

\section{INTRODUCTION}

Most of the ice discharged from the Antarctic ice sheet flows into thick, floating ice shelves that have formed in protective embayments or between shoaling seabed, where the ice shelf runs aground to form ice rumples and ice rises. Shear between ice shelves and their sides and grounded areas causes a 'back force' that inhibits ice-shelf stretching further upstream and allows the ice shelf to become thicker than if it were unrestricted. Whether this back force can also have a substantial effect on the dynamics of glaciers that flow into the ice shelf is the subject of continuing debate. Early suggestions, that ice shelves buttress their tributary glaciers and that their weakening would result in grounding-line retreat and increased glacier discharge (Hughes, 1972; Weertman, 1974; Thomas, 1977; Mercer, 1978), require ice-shelf back forces to affect glacier dynamics over large distances. Later, these suggestions were discounted, based on the contention that glacier behavior is determined mainly by local conditions, and thus is almost immune to distant perturbations (Huybrechts, 1990; Hindmarsh, 1993, 1996), that grounding-line retreat would be inhibited by increased advection of thicker ice down accelerating glaciers (Van der Veen, 1985) and that force perturbations would be balanced over quite short distances by the effects of changing basal and marginal drag as velocities change (Van der Veen, 2001). However, recent evidence of rapid acceleration of tributary glaciers soon after ice-shelf break-up along the northeastern side of the Antarctic Peninsula (Rott and others, 2002; De Angelis and Skvarca, 2003) prompts reconsideration of this issue. Here, we apply a simple force-perturbation model to Pine Island Glacier (PIG), assuming that changes in the back forces are transmitted swiftly up-glacier, in order to estimate the magnitude of such changes and to investigate their cause.

\section{FORCE-PERTURBATION MODEL}

The approach adopted here is based on two main assumptions: that glaciers 'feel' the effects of force perturbations over long distances; and that most of a glacier can be regarded as an ice shelf with a thin veneer of shearing ice separating it from its bed and sides (Thomas, 2004). For this ice, motion is primarily by longitudinal stretching, and the longitudinal strain rate $\left(\varepsilon_{x}\right)$ can be approximated by an equation similar to that derived for ice shelves: $\varepsilon_{x} \cong k(0.5 \rho g H-P)^{n}$, where $\rho$ is ice density, $g$ is gravity acceleration, $k$ is determined by ice hardness and the shape of the strain-rate tensor, $n \cong 3$ for conditions typical on glaciers, $H$ is ice thickness, and $P$ is total back pressure acting on the glacier at $x$, resulting from back forces caused by downstream basal and lateral drag and forces exerted by sea water on any floating extension (Thomas, 1973). Changes $(\Delta)$ in any of the terms on the righthand side of this equation then result in a change in $\varepsilon_{x}$ and hence glacier velocities, expressed by:

$$
\begin{aligned}
\varepsilon_{x}^{\prime} & \cong k^{\prime}\left(0.5 \rho g H^{\prime}-P^{\prime}\right)^{3} \\
& =k^{\prime}[(0.5 \rho g H-P)+(0.5 \rho g \Delta H-\Delta P)]^{3},
\end{aligned}
$$

where post-perturbation values are primed. Writing the back pressure as:

$$
P=-F / H
$$

where $-F$ is the back force per unit width, this can be simplified to:

$$
\varepsilon_{x}^{\prime} \cong k^{\prime}\left[\frac{\Delta F}{H}+\left(1-\frac{\Delta H}{H}\right)\left(\frac{e_{x}}{k}\right)^{1 / 3}+\rho g \Delta H\right]^{3}
$$




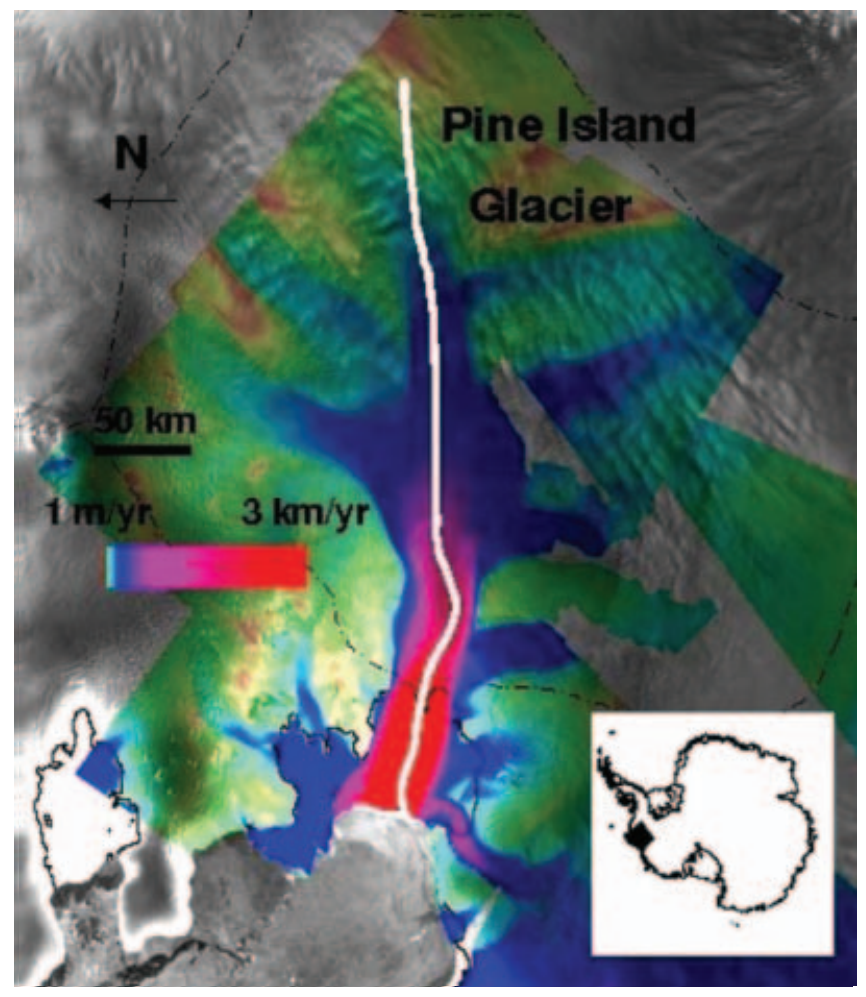

Fig. 1. Pine Island Glacier, showing the CECS/NASA flight track (white line) approximately along the glacier center line, as defined by the velocity maxima. Colors depict velocities inferred from InSAR analysis of ERS data. The 1996 grounding line is shown by the solid line approximately $60 \mathrm{~km}$ from the western end of the flight track.

and the back-force reduction per unit glacier width is:

$$
\Delta F \cong H\left[\left(\frac{\varepsilon_{x}^{\prime}}{k^{\prime}}\right)^{1 / 3}-\left(1-\frac{\Delta H}{H}\right)\left(\frac{\varepsilon_{x}}{k}\right)^{1 / 3}-\rho g \Delta H\right] .
$$

The term $k$ is:

$$
k=\theta / B^{3},
$$

where $B$ is the depth-averaged ice-stiffness parameter, and $\theta=\left(1+\gamma+\gamma^{2}+\delta^{2}+\omega^{2}\right) /(2+\gamma)^{3}$ with $\gamma=\varepsilon_{y} / \varepsilon_{x}$, $\delta=\varepsilon_{x y} / \varepsilon_{x}, \omega=\varepsilon_{x z} / \varepsilon_{x}$, with $\varepsilon_{y}$ lateral strain rate, and $\varepsilon_{x y}$ and $\varepsilon_{x z}$ shear strain rates in the horizontal and vertical planes. Here, we assume shear strain rates are small, as should be the case along a glacier center line and for fastmoving ice with low basal shear stresses. For the short section of more steeply sloping PIG this is unlikely, but even here nearly all the shear is probably within the bottom $10 \%$ of the glacier, with the above equations applying approximately to most of the ice above, where the main effect of shear is to increase the value of $\theta$ and thus effectively to soften the ice.

To a first approximation, these equations should apply to all glaciers, with $\Delta F$ representing the net effect of downstream force perturbations, including those associated with changing basal and marginal drag as velocities change. Such changes provide a negative feedback to the force perturbation, and their effect progressively increases with distance inland. However, estimates of $\Delta F$ inferred from Equation (2) include the effects of this negative feedback. For ice that is frozen to the bed, velocity changes can be related comparatively simply to changing shear stresses at the glacier bed and its margins, but for a fast-sliding glacier the relationship may be far weaker. Consequently, we expect a force perturbation to have most impact on faster-moving parts of a glacier, with a progressive decrease further inland, where near-basal ice shear predominates.

\section{APPLICATION TO PINE ISLAND GLACIER}

Pine Island Glacier (PIG) is one of the most active glaciers in the world. With speeds exceeding $2 \mathrm{~km} \mathrm{a}^{-1}$ across its $30 \mathrm{~km}$ width, it discharges about $80 \mathrm{~km}^{3}$ of ice per year (Rignot and others, 2004) into the Amundsen Sea from West Antarctica (Fig. 1).

PIG flows into a $60 \mathrm{~km}$ long ice shelf that is bounded by grounded ice. Analyses of radar-altimeter and interferometric SAR (InSAR) data from European Remote-sensing Satellites show that the ice shelf, glacier and much of its catchment basin have thinned substantially over the last few years (Shepherd and others, 2001; Zwally and others, 2002), the grounding line receded by several $\mathrm{km}$ between 1992 and 1996 (Rignot, 1998), and glacier velocities have increased by $20 \%$ or more since the 1970 s (Rignot and others, 2002; Joughin and others, 2003). The InSAR analyses yield spatially dense maps of ice velocity on the glacier, from which strain rates can be inferred, and previously sparse thickness measurements have been enhanced by joint Centro de Estudios Cientificos de Chile (CECS)/NASA airborne surveys in December 2002. Figure 2 shows the glacier profile based on these measurements, velocities and thinning rates inferred from InSAR and European Remotesensing Satellite (ERS) altimeter data, and values of basal $\left(\tau_{\mathrm{b}}\right)$ and marginal $\left(\tau_{\mathrm{m}}\right)$ shear stresses estimated using a simple model for center-line glacier velocity (e.g. Van der Veen, 1999, p. 125-127) adopted by Joughin and others (2003) for similar calculations on PIG.

$$
V_{\mathrm{c}} \cong \frac{W\left(\frac{\tau_{m}}{B}\right)^{n}}{n+1}
$$

so that

$$
\tau_{\mathrm{m}} \cong B\left[\frac{(n+1) V_{\mathrm{c}}}{W}\right]^{1 / n}
$$

and $\tau_{\mathrm{b}}$ can be estimated assuming the driving stress $(\rho g H \alpha)$ is balanced by basal and marginal stresses:

$$
\tau_{\mathrm{b}}=\rho g(H \alpha)_{\mathrm{a}}-\frac{2 H_{\mathrm{m}} \tau_{\mathrm{m}}}{W},
$$

where $(H \alpha)_{\mathrm{a}}$ is the value of $H \alpha$ averaged across glacier width $W, H_{\mathrm{m}}$ is ice thickness at the glacier margin, $V_{\mathrm{c}}$ is center-line velocity, and $\alpha$ is surface slope. We assume that $n=3$, $B=500 \mathrm{kPaa}^{1 / 3}$ (corresponding to a temperature of about $-18^{\circ} \mathrm{C}$ ) and $W=30 \mathrm{~km}$ at all points along the glacier, and thickness is constant across the glacier. The assumptions make these very approximate estimates. Upstream widening of the glacier would slightly decrease estimates of marginal shear stress and increase basal shear stresses, which would also be increased if the glacier is thinner at the margins. Nevertheless, it appears that basal shear stresses are low near the grounding line, and very low for most of the glacier upstream of about $70 \mathrm{~km}$ inland from the grounding line, in agreement with Joughin and others (2003), with high values only for the steeply sloping region downstream from $70 \mathrm{~km}$. This provides support for our assumption of ice-shelf dynamics for most of the glacier. By contrast, marginal 
shear stresses are extremely high for the ice shelf and much of the glacier.

InSAR measurements made in 1996 and 2000 (Rignot and others, 2002) show an approximately $10 \%$ increase in velocities along the $100 \mathrm{~km}$ of the grounded part of PIG inland from the grounding line (Fig. 2), and we use these observations to estimate changes in back pressure during this period. However, because this velocity increase was part of a continuing acceleration, total back-pressure changes on PIG during the recent past should be substantially larger. The velocity measurements give estimates of $\varepsilon_{x}$ for 1996 and 2000. We calculated values of $\varepsilon_{y}$ based on volume continuity, which requires that the vertical strain rate

$$
\varepsilon_{z}=-\left(\varepsilon_{x}+\varepsilon_{y}\right)=-\frac{A-M-\frac{\partial H}{\partial t}-V \frac{\partial H}{\partial X}}{H},
$$

where $A$ is surface accumulation rate, $M$ is basal melting rate (both expressed as ice thickness per unit time), $\partial H / \partial t$ is the glacier thickening rate, $V$ is velocity, $H$ is glacier thickness, and $\partial H / \partial x$ is thickness slope in the direction of ice motion. After a time interval $\Delta t$, all the variables in this equation change to primed values with, for instance, $A^{\prime}=A+\Delta A$ :

$$
\varepsilon_{z}^{\prime}=-\frac{A^{\prime}-M^{\prime}-\left(\frac{\partial H}{\partial T}\right)^{\prime}-V^{\prime}\left(\frac{\partial H}{\partial X}\right)^{\prime}}{H^{\prime}}=-\left(\varepsilon_{x}^{\prime}+\varepsilon_{y}^{\prime}\right)
$$

and

$$
\begin{aligned}
\varepsilon_{y}^{\prime} \cong & \left\{\left[A+\Delta A-M-\Delta M-\frac{\partial H}{\partial t}-\Delta\left(\frac{\partial H}{\partial t}\right)-V \frac{\partial H}{\partial x}\right.\right. \\
& \left.\left.-\Delta V\left(\frac{\partial H}{\partial x}\right)-V \Delta\left(\frac{\partial H}{\partial x}\right)\right] / H^{\prime}\right\}-\varepsilon_{x}^{\prime} \\
\cong & \frac{H}{H+\Delta t\left(\frac{\partial H}{\partial t}\right)}\left[\varepsilon_{x}+\varepsilon_{y}\right. \\
& \left.+\frac{\Delta A-\Delta M-\Delta\left(\frac{\partial H}{\partial t}\right)-\Delta V\left(\frac{\partial H}{\partial x}\right)-V \Delta\left(\frac{\partial H}{\partial x}\right)}{H}\right]-\varepsilon_{x}^{\prime} .
\end{aligned}
$$

With $\Delta(\partial H / \partial x)=\Delta t \partial(\partial H / \partial t) / \partial x$, and assuming no change in thickening rates during the interim $(\Delta(\partial H / \partial t$ $=0)$, we estimated values of $\varepsilon_{y}$ for 1996 from Equation (7), and for 2000 from Equation (9). We set $A=0.4 \mathrm{~m}^{\text {ice }} \mathrm{a}^{-1}$ (Vaughan and others, 2001), and calculated maximum values of $M$ assuming that all heat generated by motion at the bed is used for melting, using values of basal shear stress calculated from Equation (6). Although there is considerable uncertainty in our estimates of both $A$ and $M$, other terms in these equations predominate, and final results are scarcely affected by this uncertainty. To solve the equations, we used measurements of $H$ and $\partial H / \partial x$ along CECS/NASA flightlines that passed approximately along the glacier center line, as defined by the line of maximum velocity. Estimates of $\partial H / \partial t$ are for 1992-99, from Shepherd and others (2001). Our estimates of $\Delta V$ extended only about $100 \mathrm{~km}$ upstream from the grounding line, where $\Delta V / V$ was $9 \%$, similar to values further seaward. Consequently, we assumed a linear decrease in $\Delta V / V$ to zero $350 \mathrm{~km}$ inland from the grounding line. We also calculated $\Delta F$ with $\Delta V / V=0.09$ for this entire region, with little impact on resulting values. The estimated strain rates are shown in Figure 3.

Using these data, we solved Equation (2) to calculate values of $\Delta F$ along PIG shown in Figure 4. We assumed that the ice hardness $(B)$ did not change, and adopted a
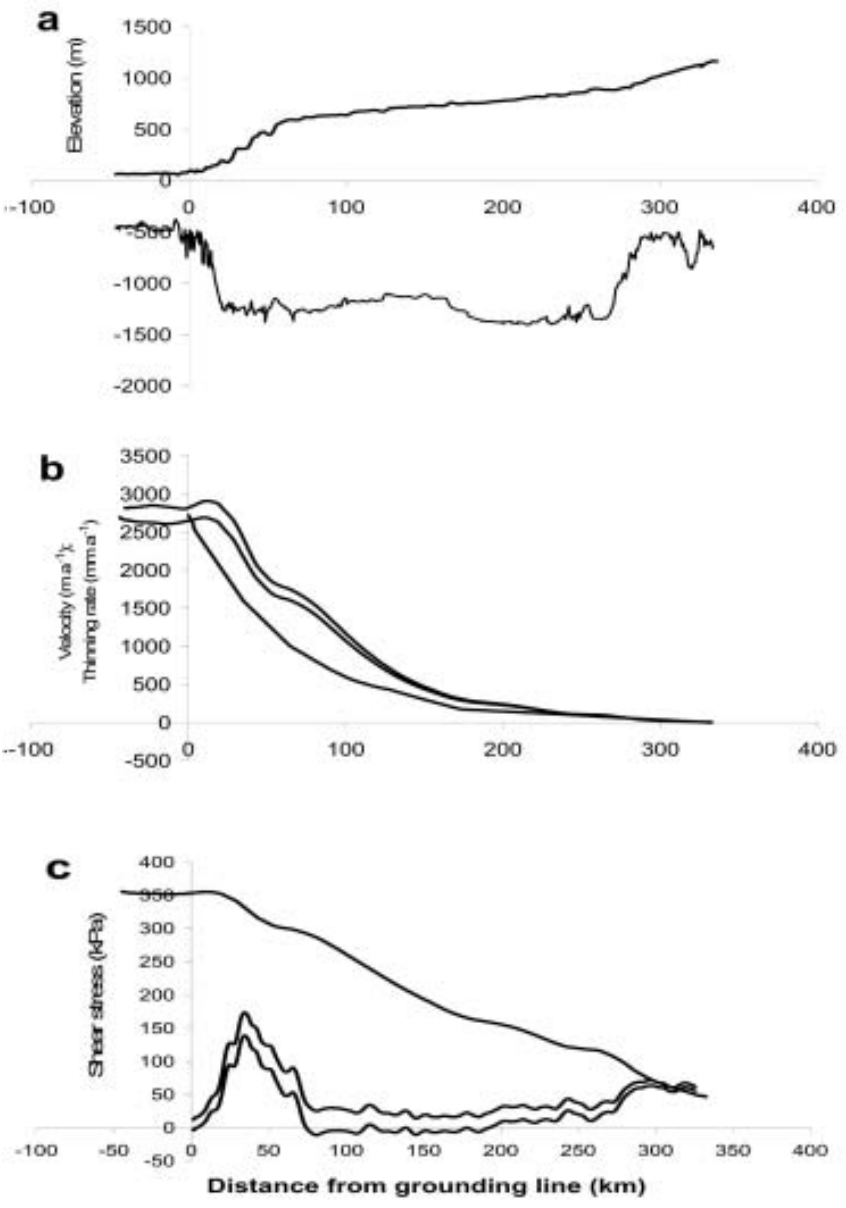

Fig. 2. (a) PIG surface and bed profiles. (b) Velocities and thinning rates along the glacier: upper line is velocity in 2000; middle line is velocity in 1996; bottom line is average thinning rate, 1992-99. (c) Calculated marginal (upper line), driving (middle line) and basal (lower line) shear stresses.

value of $B=500 \mathrm{kPaa}^{1 / 3}$. Solutions for $B=400 \mathrm{kPaa}^{1 / 3}$ and $600 \mathrm{kPaa}^{1 / 3}$ gave values of $\Delta F$ that differed by $<7 \%$ from those in Figure 4. Lacking accurate estimates of thickening rates and basal melting rates on the ice shelf, we were unable to include this part of the glacier in the analysis.

Errors in solving Equation (2) are determined by uncertainty in thinning rates and strain rates. They are typically about $10 \mathrm{MN} \mathrm{m}^{-1}$, but larger in areas of strong lateral convergence or longitudinal compression where $\gamma<-1$. In such areas the magnitude and even the sign of $\theta$ (and therefore $k$ and $k^{\prime}$ ) are highly sensitive to small errors in strain rates. For PIG, this applies within about $10 \mathrm{~km}$ of the grounding line, where results should be viewed with caution. The region of high basal shear stress shown in Figure 2 coincides closely with the peak in back-force reduction, and here shear strain rates $\left(\varepsilon_{x z}\right)$ near the bed may be as large as longitudinal strain rates, but decrease rapidly above the bed. This would increase the value of $\theta$, making the calculated peak values of $\Delta F$ perhaps $10 \%$ too high. Inland of about $200 \mathrm{~km}$, the force reduction progressively decreases to zero near $350 \mathrm{~km}$, resulting from the assumption that velocity increase and thinning rates decrease to zero here.

Total back-force reduction is the product of $\Delta F$ and local glacier width, which is about $30 \mathrm{~km}$ over the first $50 \mathrm{~km}$ of 


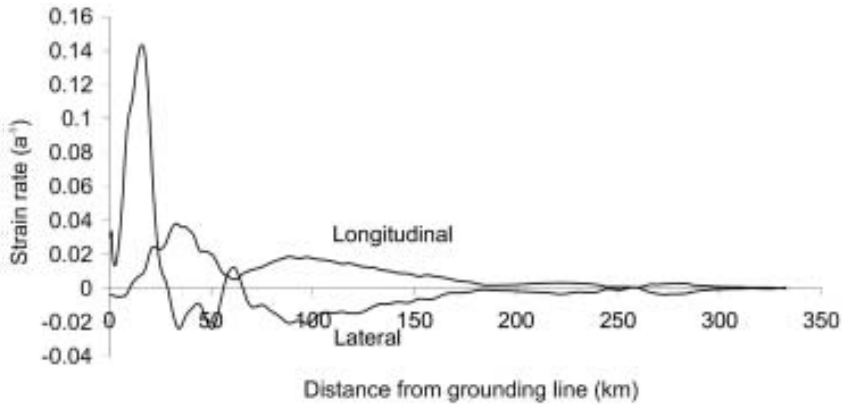

Fig. 3. Longitudinal strain rates derived from observed 1996 velocities, and corresponding lateral strain rates calculated as described in the text.

the glacier. Further inland, large tributaries join the glacier, increasing the width over which the force reduction is distributed. This is consistent with the decrease in $\Delta F$ in this region, but much of this decrease reflects the effects of increasing marginal drag as velocities increased. Indeed, the 10\% velocity increase between 1996 and 2000 should have increased marginal drag by about $3 \%$, and this was probably responsible for most of the $60 \mathrm{MN} \mathrm{m}^{-1}$ decrease in $\Delta F$ from its maximum value at $35 \mathrm{~km}$ inland from the grounding line to its value $65 \mathrm{~km}$ further inland. This implies that:

$$
65000 \frac{\left(0.06 H_{\mathrm{m}} \tau_{\mathrm{m}}\right)_{\mathrm{a}}}{W}=60 \mathrm{MN} \mathrm{m}^{-1},
$$

where $\left(H_{\mathrm{m}} \tau_{\mathrm{m}}\right)_{\mathrm{a}}$ is the value of $\left(H_{\mathrm{m}} \tau_{\mathrm{m}}\right)$ averaged over $65 \mathrm{~km}$ and $W \cong 30 \mathrm{~km}$, so that

$$
\left(H_{\mathrm{m}} \tau_{\mathrm{m}}\right)_{\mathrm{a}} \cong 460 \mathrm{MN} \mathrm{m}^{-1} .
$$

From Figure 2, the marginal shear stress averaged over this region is about $300 \mathrm{kPa}$, which would require the average marginal ice thickness to be $1500 \mathrm{~m}$, compared to the approximately $1800 \mathrm{~m}$ measured at the glacier center line (Fig. 2). The CECS/NASA thickness measurements certainly show marginal ice to be thinner, but it is also possible that $\tau_{\mathrm{m}}$ is less than shown in Figure 2 if marginal ice is softened by strain heating and/or ice-fabric development.

\section{DISCUSSION}

The results in Figure 4 show a rapid increase in $\Delta F$ from perhaps $30 \mathrm{MN} \mathrm{m}^{-1}$ at the grounding line to about $100 \mathrm{MN} \mathrm{m}^{-1} 35 \mathrm{~km}$ inland, with most of the increase in the first $25 \mathrm{~km}$. This suggests that much of its cause lies within this region, which is an area of partial grounding (Thomas, 1984; Corr and others, 2001) known as an 'ice plain'. Using measurements made in 1981 and 1998, Corr and others (2001) showed that most of this ice plain had surface elevations $<50 \mathrm{~m}$ above that at which the ice would become afloat (flotation elevation). The CECS/NASA observations in late 2002 show it to be $<40 \mathrm{~m}$ above flotation elevation (Fig. 5). Although the difference could reflect uncertainties in some of the earlier data, it is consistent with the high thinning rates inferred for this part of the glacier from satellite radar-altimeter data (Shepherd and others, 2001). A probable explanation for the back-force reduction is progressive ungrounding of this ice plain. Estimated basal shear stresses along our flight-line over the ice plain (Fig. 2) averaged almost $30 \mathrm{kPa}$, contributing a total back force of $700 \mathrm{MN} \mathrm{m}^{-1}$ in 2002 . Thus, a back-force reduction

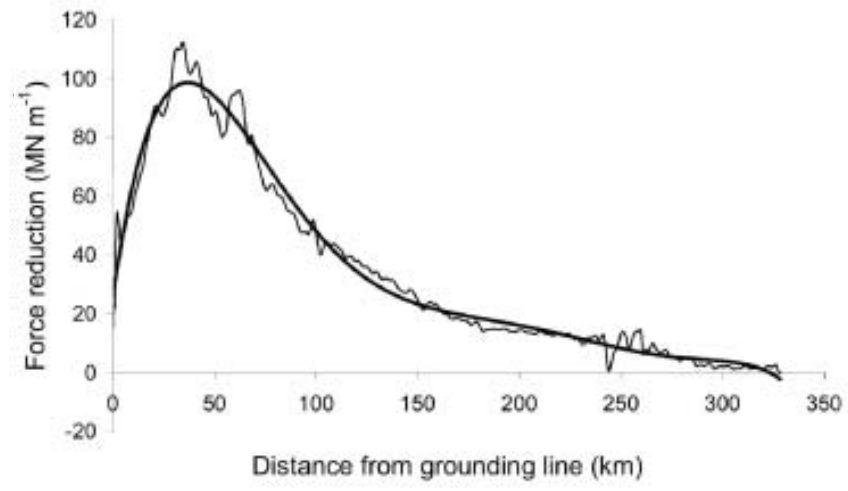

Fig. 4. Force reduction/unit width $(\Delta F)$ on PIG, consistent with velocity increases and thickness changes between 1996 and 2000, plotted against distance from the grounding line. Uncertainty limits are large, so the variation of $\Delta F$ is probably adequately represented by the bold line.

of $70 \mathrm{MN} \mathrm{m}^{-1}$ between 1996 and 2000 represents $10 \%$ of potential future reductions if the recent thinning of about $2 \mathrm{~m} \mathrm{a}^{-1}$ continues and the entire ice plain becomes afloat.

Near the grounding line, errors are large, but the decreasing trend in $\Delta F$ towards the grounding line exhibited by results further inland suggests that the grounding-line value is small. An independent estimate can be obtained from observations showing that the ice shelf thinned by about $2.5 \mathrm{~m} \mathrm{a}^{-1}$ during the $1990 \mathrm{~s}$ (personal communication from H.J. Zwally, 2003). The ice shelf is approximately $60 \mathrm{~km}$ long, so the area of ice shelf in contact with its margins decreased by about $0.3 \mathrm{~km}^{2} \mathrm{a}^{-1}$. Assuming a marginal shear stress of $350 \mathrm{kPa}$, as shown in Figure 2, this represents a total decrease in back force of $100 \mathrm{GN} \mathrm{a}^{-1}$. Distributed over the glacier width of $30 \mathrm{~km}$, this is equivalent to an average back-force decrease of $3.5 \mathrm{MN} \mathrm{m}^{-1} \mathrm{a}^{-1}$, or $\Delta F \cong 14 \mathrm{MN} \mathrm{m}^{-1}$ between 1996 and 2000. Consequently, the effects of ice-shelf thinning are consistent with low $\Delta F$ at the grounding line. But a change in ice-shelf length also affects $\Delta F$. The ice shelf is about $500 \mathrm{~m}$ thick near its calving front, so removal of $1 \mathrm{~km}$ in length represents a reduction in marginal area by $1 \mathrm{~km}^{2}$ and a back-force reduction of $10 \mathrm{MN} \mathrm{m}^{-1}$. In reality, the ice front actually advanced between 1996 and 2000 (Rignot, 2002). But a large transverse rift was observed in 2000, several $\mathrm{km}$ upstream from the 1996 ice-front position. Moreover, thinning of the ice shelf may be freeing it from the buffering influence of an ice rise on the northern side of the ice shelf about $5 \mathrm{~km}$ upstream from the rift. Consequently, it is not clear whether changes in the ice shelf between 1996 and 2000 would have increased or decreased back forces at the grounding line.

Over the longer term, the calving front of the ice shelf has remained broadly in the same position since 1947 (Rignot, 2002), but with new rifts forming during the 1990s, and substantial retreat of ice shelf immediately to the north. These changes may have been associated with increased basal melting postulated by Rignot and Jacobs (2002), reducing ice-shelf back pressure sufficiently to increase creep-thinning rates which, together with the basal melting, would explain the grounding-line retreat observed between 1992 and 1994. Since then, continued thinning has progressively ungrounded the ice plain, and another substantial retreat of the grounding line is likely within the 


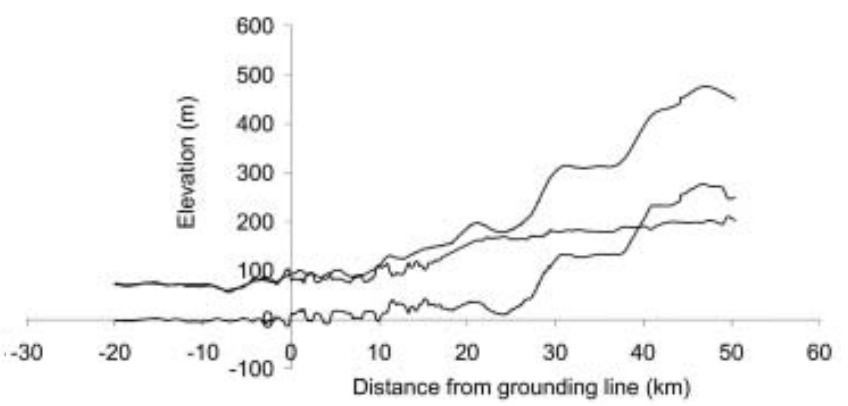

Fig. 5. Profiles near the grounding line of PIG, based on measurements in December 2002. The upper line is the surface elevation; the middle line is the 'hydrostatic elevation', at which the glacier would become afloat; and the lower line is the difference between these two elevations, which is the thinning required to float the ice. Over the $25 \mathrm{~km}$ nearest the grounding line, the maximum surface elevation above hydrostatic elevation is $<40 \mathrm{~m}$, with an average value of $20 \mathrm{~m}$. This region is referred to as an 'ice plain', and within it there are sections that are either floating or very close to flotation. Continued thinning will enlarge these sections, and the most seaward $10 \mathrm{~km}$ of the ice plain appears to be particularly vulnerable, indicating a probable $10 \mathrm{~km}$ grounding-line retreat very soon, followed by delayed flotation of the remaining ice plain. Such intermittent ungrounding could explain the sporadic velocity increases reviewed by Joughin and others (2003).

next few years. Overall, the sequence of ice-shelf thinning, grounding-line retreat and ice-plain ungrounding was probably initiated by increased basal melting associated with a warmer ocean.

Observations reviewed by Joughin and others (2003) show that PIG has been accelerating since at least the late 1970 s/early 1980 s, with a total velocity increase of $>20 \%$. Our analysis refers to just 4 years of this period, when about half of the velocity increase occurred. But over the longer period, the glacier probably thinned more than between 1996 and 2000, implying, from Equation (2), that the total force reduction since 1980 is more than double the values shown in Figure 4.

\section{THE FUTURE}

The future of PIG is also of interest. If there is no additional force reduction, the glacier will thin sufficiently for the force reduction to be balanced by a drop in the driving force, determined by glacier thickness, until $\varepsilon_{x}^{\prime} \rightarrow \varepsilon_{x}$ and glacier velocities decrease towards their pre-perturbation values. By then the glacier will be thinner, so new equilibrium velocities will be proportionally higher, in order to balance upstream snowfall. An upper estimate of future thinning $\left(-\Delta H_{\mathrm{f}}\right)$ can be obtained from Equation (2), by setting $\varepsilon_{x}^{\prime} / k^{\prime}=\varepsilon_{x} / k$ and assuming $\Delta H_{\mathrm{f}} / H \ll 1$, to yield:

$$
\Delta H_{\mathrm{f}} \cong-\frac{\Delta F}{\rho g H} \text {. }
$$

For the region where $\Delta F$ reaches a maximum of about $100 \mathrm{MN} \mathrm{m}^{-1}, H \cong 1700 \mathrm{~m}$, and $\Delta H_{\mathrm{f}} \cong-7 \mathrm{~m}$ in an area where recent thinning rates have approximated $2 \mathrm{ma}^{-1}$. Continued thinning at this rate will soon balance the force reduction and lead to a reduction in glacier velocities if there is no further increase in $\Delta F$. But thinning will also cause a large fraction, if not all, of the remaining ice plain to

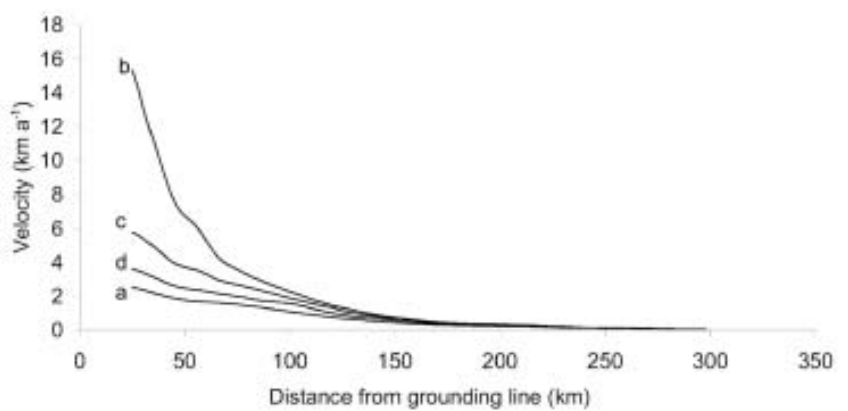

Fig. 6. PIG ice velocities. Curve a was derived from 1996 data; b shows calculated velocities for instantaneous flotation of the ice plain; c shows velocities after progressive ungrounding of the ice plain over about 8 years, neglecting negative feedback from increasing marginal shear stresses; and $d$ shows velocities after progressive ungrounding over 11 years, taking account of this feedback.

become afloat within the next few years, increasing the maximum value of $\Delta F$ above its value in 2002 . This increase would be less than the $700 \mathrm{MN} \mathrm{m}^{-1}$ currently exerted by the ice plain because associated velocity increases would also increase shear stresses at the sides of the ice shelf, as implied by Equation (5). In order to estimate velocity increases associated with this, we solved Equation (1) along the glacier $(x)$, with $\Delta F(x)$ decreasing up-glacier, from its maximum value $\left(\Delta F_{\mathrm{m}}\right)$ immediately upstream of the ice plain, in a manner similar to that depicted in Figure 4. Initially, we solved Equation (1) for instantaneous flotation of the ice plain $(\Delta H=0)$, assuming no increase in marginal drag $\left(\Delta F_{\mathrm{m}}=700 \mathrm{MN} \mathrm{m}^{-1}\right)$, and that velocity increase would be sufficient to make $\varepsilon_{x}^{\prime} \gg \varepsilon_{y}^{\prime}$, so that $\theta^{\prime} \cong 0.125$. We used the calculated values of $\varepsilon_{x}^{\prime}$ to improve estimates of $\alpha^{\prime}$ and hence $\theta^{\prime}$ in order to calculate an improved velocity profile, and repeated this several times to converge to the upper curve in Figure 6.

Clearly, instant flotation of the ice plain is unrealistic, but it allowed us to estimate upper values for ice-thinning rates along the glacier, which were then used to infer average values of thinning rates over the period needed to float the ice plain $(\Delta H=-40 \mathrm{~m})$. This procedure was also repeated several times, altering $\theta^{\prime}$ each time, until assumed thinning rates and values of $\theta^{\prime}$ were consistent with those implied by the velocity increase associated with $\Delta F_{\mathrm{m}}$, with and without taking account of increased marginal drag consistent with Equation (5) and corresponding to the calculated velocity increase. The results (Fig. 6) show velocities at the inland limit of the ice plain increasing to $15 \mathrm{~km} \mathrm{a}^{-1}$ for instantaneous flotation of the ice plain, and almost $6 \mathrm{kma}^{-1}$ after 8 years of progressive ungrounding if there is no increase in marginal drag. Taking account of increasing marginal drag, calculated velocities rise to $3.6 \mathrm{~km} \mathrm{a}^{-1}$ over the 11 year period needed to thin the ice sufficiently for complete flotation of the ice plain. Although this calculation is very approximate, such a velocity increase will be readily apparent, providing an early opportunity to test results from the simple analysis adopted here.

These estimates represent conditions soon after flotation of the ice plain. As the glacier thins and the magnitude of $\Delta H$ in Equation (1) increases, velocities and the discharge flux will fall unless there is a further decrease in back forces. 
Such an increase is quite likely. Flotation of the ice plain will shift the grounding line over seabed that is $>1200 \mathrm{~m}$ below sea level, where the bed is nearly horizontal over a distance of $>200 \mathrm{~km}$ upstream, and basal shear stresses are very small (Fig. 2).

\section{CONCLUSIONS}

The equations used here are based on the assumption that perturbations in the forces acting on a glacier are transmitted over large distances, to affect longitudinal strain rates far away from the cause of the perturbation, and that equations similar to those governing ice-shelf creep can be used to estimate resulting effects. This differs from most approaches to glacier dynamics, which focus on local conditions as the dominant influence. These conditions certainly determine local driving stresses, which are important in controlling shear within the ice. But the longitudinal creep of most of the glacier must also be consistent with longitudinal forces, and here we have focused on these, with local conditions contributing by determining the magnitude of the forces. We justify the ice-shelf approximation by regarding most of a glacier as a slab of ice 'floating' on a thinner layer of shearing or sliding ice. Clearly, this is a simplifying approximation, but the results presented provide an opportunity to test whether it is a reasonable working assumption. The recently observed thinning and acceleration of PIG can readily be explained by changes in partially grounded ice plain that probably occurred during the period covered by the observations. We estimate the $10 \%$ velocity increase between 1996 and 2000 to have been caused primarily by ungrounding of only about $10 \%$ of the ice plain. But recent thinning rates are sufficient to unground the entire plain within the next few years, and this could result in a velocity increase from 2.7 to $3.6 \mathrm{~km} \mathrm{a}^{-1}$. Thereafter, sustained high velocities are quite possible, if the grounding line then retreats over the glacier's nearly horizontal bed.

\section{ACKNOWLEDGEMENTS}

This work was made possible by the availability of PIG icethickness and surface elevation data acquired by joint CECS/ NASA airborne surveys in November/December 2002. We are indebted to pilots, crew members, technicians and staff from the Armada de Chile, from University of Kansas, from NASA Wallops Flight Facility and from CECS for making this work both a success and a delightful experience. We also thank the scientific editor, R. Mulvaney, and reviewers for many helpful suggestions, and an anonymous reviewer of a related paper for identifying an earlier error in our forceperturbation equations. Financial support for preparing this paper was provided by NASA's Cryospheric Processes Program and ICESat Project, and by CECS, through Fundación Andes and the Millennium Science Initiative.

\section{REFERENCES}

Corr, H. F. J., C. S. M. Doake, A. Jenkins and D. G. Vaughan. 2001. Investigations of an 'ice plain' in the mouth of Pine Island Glacier, Antarctica. J. Glaciol., 47(156), 51-57.

De Angelis, H. and P. Skvarca. 2003. Glacier surge after ice shelf collapse. Science, 299(5612), 1560-1562.
Hindmarsh, R.C.A. 1993. Qualitative dynamics of marine ice sheets. In Peltier, W. R., ed. Ice in the climate system. Berlin, etc., Springer-Verlag, 67-99. (NATO ASI Series I: Global Environmental Change 12.)

Hindmarsh, R.C.A. 1996. Stability of ice rises and uncoupled marine ice sheets. Ann. Glaciol., 23, 105-115.

Hughes, T. 1972. Is the West Antarctic ice sheet disintegrating? Columbus, $\mathrm{OH}$, Ohio State University. Ice Streamline Cooperative Antarctic Project. (ISCAP Bulletin 1.)

Huybrechts, P. 1990. The Antarctic ice sheet during the last glacial-interglacial cycle: a three-dimensional experiment. Ann. Glaciol., 14, 115-119.

Joughin, I., E. Rignot, C. E. Rosanova, B. K. Lucchitta and J. Bohlander. 2003. Timing of recent accelerations of Pine Island Glacier, Antarctica. Geophys. Res. Lett., 30(12), 1706. (10.1029/ 2003GL017609.)

Mercer, J. H. 1978. West Antarctic ice sheet and $\mathrm{CO}_{2}$ greenhouse effect: a threat of disaster. Nature, 271(5643), 321-325.

Rignot, E.J. 1998. Fast recession of a West Antarctic glacier. Science, 281(5376), 549-551.

Rignot, E. 2002. Ice-shelf changes in Pine Island Bay, Antarctica, 1947-2000. J. Glaciol., 48(161), 247-256.

Rignot, E. and S. S. Jacobs. 2002. Rapid bottom melting widespread near Antarctic ice sheet grounding lines. Science, 296(5575), 2020-2023.

Rignot, E., D. G. Vaughan, M. Schmeltz, T. Dupont and D. MacAyeal. 2002. Acceleration of Pine Island and Thwaites Glaciers, West Antarctica. Ann. Glaciol., 34, 189-194.

Rignot, E. and 11 others. 2004. Improved estimation of the mass balance of the glaciers draining into the Amundsen Sea sector of West Antarctica from the CECS/NASA 2002 campaign. Ann. Glaciol., 39 (see paper in this volume).

Rott, H., W. Rack, P. Skvarca and H. De Angelis. 2002. Northern Larsen Ice Shelf, Antarctica: further retreat after collapse. Ann. Glaciol., 34, 277-282.

Shepherd, A., D. J. Wingham, J. A. D. Mansley and H. F. J. Corr. 2001. Inland thinning of Pine Island Glacier, West Antarctica. Science, 291(5505), 862-864.

Thomas, R. H. 1973. The creep of ice shelves: theory. J. Glaciol., 12(64), 45-53

Thomas, R. H. 1977. Calving bay dynamics and ice sheet retreat up the St. Lawrence Valley system. Géogr. Phys. Quat., 31(3-4), 347-356.

Thomas, R. H. 1984. Ice sheet margins and ice shelves. In Hansen, J.E. and T. Takahashi, eds. Climate processes and climate sensitivity. Washington, DC, American Geophysical Union, 265-274. (Geophysical Monograph 29.) (Maurice Ewing Series 5.)

Thomas, R. H. 2004. Force-perturbation analysis of recent thinning and acceleration of Jakobshavn Isbræ, Greenland. J. Glaciol. 50(168), 57-66.

Van der Veen, C. J. 1985. Response of a marine ice sheet to changes at the grounding line. Quat. Res., 24(3), 257-267.

Van der Veen, C.J. 1999. Fundamentals of glacier dynamics. Rotterdam, etc., A.A. Balkema Publishers.

Van der Veen, C. J. 2001. Greenland ice sheet response to external forcing. J. Geophys. Res., 106(D24), 34,047-34,058.

Vaughan, D. and 9 others. 2001. A review of Pine Island Glacier, West Antarctica: hypotheses of instability vs. observations of change. In Alley, R. and R. Bindschadler, eds. The West Antarctic Ice Sheet, behavior and environment. Antarctic Research Series 77, 237-256.

Weertman, J. 1974. Stability of the junction of an ice sheet and an ice shelf. J. Glaciol., 13(67), 3-11.

Zwally, H. J. and 15 others. 2002. ICESat's laser measurements of polar ice, atmosphere, ocean and land. J. Geodyn., 34(3-4), 405-445. 